\title{
JUURNAL_RU
}

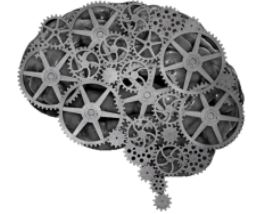

COMPANY GROUP "INTELLEKT"

Незнамов М.H. Саратовский филиал Самарского медицинского университета «РЕАВИЗ»

Саратов, Россия

doi: 10.18411/lj2016-3-27

\section{Оценка сосудистой проницаемости методом активной радиометрии}

Учитывая высокую информативность показателей сосудистой проницаемости в дифференциальной диагностике патологических изменений внутренних органов, представляется актуальным поиск неинвазивных методов ее оценки. Одним из новых методов диагностики состояния внутренних органов является активная радиометрия (AP), позволяющая исследовать интенсивность транскапиллярного обмена (ТКО) воды и белка в тканях [1-3]. Учитывая высокую актуальность поиска новых методов оценки состояния внутренних органов, целью исследования явилось изучение возможностей АР в оценке сосудистой проницаемости, с точки зрения использования данного метода в клинической практике.

Материалы и методы исследования. Исследование проводилось в соответствии с «Хельсинской декларацией о гуманном отношении к животным» на 45 крысах Wistar обоего пола массой 200-230 г., находившихся в контролируемых условиях не менее 2-х недель до эксперимента. Изучение возможности неинвазивной оценки сосудистой проницаемости методом АР осуществлялось на модели адреналинового отека легких [4].

Для оценки изменения степени сосудистой проницаемости в эксперименте, сразу после гибели животных немедленно выделяли легкие, с определением их чистого веса. Тяжесть сосудистых нарушений определялась по легочному 
индексу (ЛИ = вес легкого х 100 / масса тела) $[4,5]$.

Для оценки интенсивности стимулированного СВЧ-излучения органов грудной полости использовали радиоэлектронный комплекс «Аквафон» [6-9]. Статистическую обработку проводили в программе STATISTICA 7,0. Статистическую значимость (р) межгрупповых различий оценивали с помощью критерия Колмогорова-Смирнова.

Результаты исследования. Линейный регрессионный анализ позволил оценить степень связи ВА тканей легких и ЛИ. В процессе анализа было получено регрессионное уравнение следующего вида: $\mathrm{BA}=-5,265+6,9018 *$ ЛИ. Коэффициент линейной корреляции ЛИ и ВА составил 0,99 ед., при этом более 97\% всей дисперсии ВА, обусловлено изменением ЛИ. Адекватность регрессионной модели подтверждается нормальным распределением ее остатков (критерий Шапиро-Уилка $\mathrm{W}=0,9, \mathrm{p}=0,11$ ) и низким коэффициентом их корреляции $(\mathrm{r}=0,31)$.

Результаты исследования указывают на определяющую роль ТКО воды в формировании ВА тканей. Динамичный характер изменений ВА при развитии нарушений сосудистой проницаемости, тесно связан с процессом перераспределения жидкости между сосудистым руслом и тканевой жидкостью. Информативность диагностики по результатам ROC-анализа, составила 93,1\% (95\% ДИ 91,1-95,3\%), чувствительность - 85,3\%, специфичность - 96,2\%.

Заключение. Разработка неинвазивной технологии состояния альвеолярнокапиллярной проницаемости позволяет осуществлять диагностику патологических состояний, в основе которых лежат экссудативные процессы [10-15]. Возможность мониторинга патологических изменений методом АР позволит избежать ионизирующих излучений, способствуя более частому применению метода для оперативного контроля патологического процесса. Учитывая, что активность ТКО отражает тонкие функциональные изменения регуляции сосудисто-тканевого метаболизма, последние могут быть оценены 
по изменению ВА. Высокая чувствительность АР позволяет использовать данный метод не только для оценки функционального состояния тканей и органов, но и для выявления постклинических форм воспалительных и дегенеративно-дистрофических процессов, а так же острой хирургической патологии воспалительной этиологии [16-22]. 


\section{Литература:}

1. Системные подходы в биологии и медицине (системный анализ, управление и обработка информации) / В.И. Стародубов и др. под ред. А.А. Хадарцева, В.М. Еськова, А.А. Яшина, К.М. Козырева. Тула: ООО РИФ «ИНФРА», 2008. $372 \mathrm{c}$.

2. Избранные технологии диагностики: Монография / В.М. Еськов и др.; под ред. А.А. Хадарцева, В.Г. Зилова, Н.А. Фудина. Тула: ООО РИФ «ИНФРА», 2008. $296 \mathrm{c}$.

3. Терехов И.В. Оценка сосудистой проницаемости с помощью активной радиометрии // Аспирантский вестник Поволжья. 2009. № 7-8. С. 187-190.

4. Терехов И.В., Дзюба М.А., Наджарьян Л.С. Оценка альвеолярнокапиллярных нарушений при развитии тяжелого гемодинамического отека легких у крыс и их коррекция с помощью СВЧ-излучения // Саратовский научно-медицинский журнал. 2011. Т. 7. № 2. С. 389-392.

5. Исследование состояния транскапиллярного обмена и его коррекция с помощью радиоэлектронного лечебно-диагностического комплекса «Аквафон» / М.С. Громов, И.В. Терехов, С.С. Бондарь и др. // Биомедицинская радиоэлектроника. 2010. № 3. С. 43-48.

6. Терехов И.В. Транс-резонансная функциональная топография в диагностике заболеваний органов дыхания (новый метод обработки информации): автореф. дисс. канд. мед. наук, Тула, 2007. 24 с.

7. Применение транс-резонансной функциональной топографии с целью оптимизации диагностической тактики у пациентов с подозрением на острый панкреатит и его осложнения / А.И. Лобаков, М.С. Громов, С.А. Дубовицкий и др. // Хирург. 2008. № 8. С. 22-33.

8. Идентификация и дифференциация костных новообразований методом активной радиометрии / М.Н. Незнамов, В.А. Зайцев, Н.А. Ругина и др. // Вестник новых медицинских технологий. Электронное издание. 2015. Т. 9. № 2. C. 20.

9. Бецкий О.В. Пионерские работы по миллиметровой электромагнитной биологии, выполненные в ИРЭ РАН // Биомедицинские технологии и радиоэлектроника. 2003. №8. С. 11-20.

10. Использование радиоволнового зондирования водосодержащих сред миокарда у больных с артериальной гипертензией / И.В. Терехов, К.А. Солодухин, В.С. Никифоров, А.В. Ломоносов // Российский кардиологический журнал. 2013. № 5 (103). С. 40-43. 
11. Терехов И.В., Логаткина А.В., Бондарь С.С. Функциональное состояние миокарда и его связь с состоянием водосодержащих сред органов грудной клетки при инфильтративных процессах в легких // Stredoevropsky Vestnik pro Vedu a Vyzkum. 2015. T. 51. C. 3.

12. Громов М.С., Аржников В.В., Терехов И.В. Возможности оценки функционального состояния организма с помощью собственного радиоизлучения нетепловой природы // Медицинский вестник МВД. 2008. № 5 (36). С. 38-43.

13. Возможность использования активной СВЧ-радиометрии для оценки альвеолярно-капиллярной проницаемости в эксперименте / И.В. Терехов, К.А. Солодухин, В.В. Аржников и др. // Регионарное кровообращение и микроциркуляция. 2011. Т. 10. № 4. С. 83-86.

14. Применение метода ТРФ-топографии в диагностике воспалительных изменений нижних отделов респираторного тракта / И.В. Терехов, М.С. Громов, В.К. Парфенюк и др. // Саратовский научно-медицинский журнал. 2008. T. 4. № 1. С. 79-83.

15. Терехов И.В., Парфенюк В.К. Мониторинг инфильтративных процессов нижних отделов респираторного тракта у пациентов с внебольничной пневмонией методом люминесцентного анализа в радиодиапазоне // Вестник восстановительной медицины. 2009. № 3. С. 46-50.

16. Интегральная оценка воспалительного процесса у больных внебольничной пневмонией методом активной радиометрии / В.В. Аржников, В.Б. Лифшиц, В.К. Парфенюк, И.В. Терехов // Саратовский научномедицинский журнал. 2011. Т. 7. № 4. С. 817-822.

17. Громов М.С., Терехов И.В. Характеристика системного воспалительного ответа у больных внебольничной пневмонией в динамике при помощи активной СВЧ-радиометрии // Казанский медицинский журнал. 2010. Т. 91. № 5. С. 611-614.

18. Дифференциальная диагностика заболеваний грудной клетки с помощью транс-резонансной функциональной топографии / И.В. Терехов, В.И. Петросян, М.С. Громов и др. // Вестник медицинского института "РЕАВИЗ": реабилитация, врач и здоровье. 2013. № 3 (11). С. 18-26.

19. Аржников В.В., Терехов И.В., Громов М.С. Диагностика и мониторинг инфильтративных процессов в грудной полости с помощью люминесцентного излучения водосодержащих сред // Медицинский вестник МВД. 2009. № 2 (39). С. 40-46. 
20. Технология динамической оценки воспалительного процесса с помощью активной резонансной радиометрии / И.В. Терехов, М.С. Громов, В.И. Петросян и др. // Вестник новых медицинских технологий. 2010. Т. 17. № 1. С. $135-137$.

21. Использование активной резонансной СВЧ радиометрии для идентификации и мониторинга иммуно-воспалительных изменений у больных с острыми инфильтративно-воспалительными процессами нижних отделов респираторного тракта / М.С. Громов, И.В. Терехов, С.Е. Попович и др. // Вестник новых медицинских технологий. 2011. Т. 18. № 1. C. $38-41$.

22. Громов М.С., Аржников В.В., Терехов И.В. Мониторинг воспалительного процесса при внебольничной пневмонии с помощью СВЧ-излучения органов грудной полости // Медицинский вестник МВД. 2010. № 5 (48). С. 16-17.

23. Трансрезонансная функциональная топография в оптимизации диагностики у пациентов с подозрением на острую воспалительную патологию органов брюшной полости / Громов М.С., Масляков В.В., Брызгунов А.В. и др. // Анналы хирургии. 2008. № 6. С. 60-63. 